Artículo de Investigación

\title{
El calzado de seguridad en el Ecuador, factores que inciden en la calidad del producto y en la productividad de las organizaciones
}

\author{
Safety footwear in Ecuador, factors that affect the quality of the product and the \\ productivity of organizations \\ Carlos Burgos* (D), Patricio Villacrés ${ }^{(\mathbb{D})}$, Mario Cabrera ${ }^{\mathbb{D}}$, Wilfrido Salazar ${ }^{\mathbb{D}}$ \\ Carrera de Ingeniería Industrial, Facultad de Ingeniería, Universidad Nacional de Chimborazo, Riobamba, Ecuador, 060108; \\ pvillacres@unach.edu.ec; mcabrera@unach.edu.ec; hsalazar@unach.edu.ec
}

*Correspondencia: cburgos@unach.edu.ec

\begin{abstract}
Citación: Burgos, C., Villacrés, P., Cabrera, M., \& Salazar, W., (2022). El calzado de seguridad en el Ecuador, factores que inciden en la calidad del producto y en la productividad de las organizaciones. Novasinergia. 5(1). 61-82.
\end{abstract}

https://doi.org/10.37135/ns.01.09.05

Recibido: 05 abril 2021

Aceptado: 11 agosto 2021

Publicación: 31 enero 2022

Novasinergia

ISSN: 2631-2654

\footnotetext{
(cc) (\$)

Copyright: 2022 derechos otorgados por los autores a Novasinergia.

Este es un artículo de acceso abierto distribuido bajo los términos $\mathrm{y}$ condiciones de una licencia de Creative Commons Attribution (CC BY NC).

(http://creativecommons.org/licens es/by/4.0/)
}

Resumen: Se muestra un análisis situacional de las empresas que producen calzado de seguridad industrial en el Ecuador; se considera un análisis de entorno y un análisis de su situación financiera. El estudio se complementa con la evaluación de los procesos productivos considerando los factores: materia prima (MP), mano de obra (MO), medio ambiente (MA), máquinas (MAq), métodos de trabajo (MT) para mostrar como estos inciden en la productividad; se determinan además los niveles de calidad del producto obtenidos a través de ensayos que pretenden medir el cumplimiento de parámetros considerados en la norma INEN - ISO 20346:2014 del Servicio Ecuatoriano de Normalización (INEN). Los resultados muestran que el $80 \%$ de las empresas consideradas son familiares, superan los 25 años de permanencia en el mercado, el $60 \%$ de ellas cuentan con capital propio y otro $40 \%$ han contraído deudas para operar. En los ensayos aplicados al producto se evidencia que tiene niveles de cumplimiento superiores al $88 \%$ y se evalúan en promedio 10 parámetros. El factor que más incide en la productividad es la mano de obra (MO) debido a que es un elemento transversal de los procesos.

Palabras clave: Análisis situacional, calzado de seguridad, calidad, estabilidad económica, factores de producción, índice de crecimiento económico, productividad.

Abstract: A situational analysis of the companies that produce industrial safety footwear in Ecuador is shown; an analysis of the environment and their financial situation are considered. The study is complemented with the evaluation of the production processes considering the factors: raw material (PM), labor (MO), environment (MA), machines (MAq), work methods (MT) to show how these affect productivity; The quality levels of the product obtained are also determined through tests that aim to measure compliance with the parameters considered in the INEN - ISO 20346: 2014 standard of the Ecuadorian Standardization Service (INEN). The results show that $80 \%$ of the companies considered are family-owned, have been in the market for more than 25 years, $60 \%$ of them have their own capital, and another $40 \%$ have incurred debts to operate. In the tests applied to the product, it is evidenced that it has compliance levels higher than $88 \%$, and an average of 10 parameters are evaluated. The factor that most affects productivity is labor (OM) because it is a crosscutting element of the processes.

Keywords: Economic growth rate, economic stability, production factors, productivity, quality, safety footwear, situational analysis. 


\section{Introducción}

A nivel mundial entre los años 2010 y 2014 se dio un incremento del 15\% en la producción total de calzado; posteriormente en los años 2015 y 2016 la producción se mantuvo en los 23000 millones de pares y en el año 2017 se produjeron 23500 millones de pares a nivel mundial (Chan, Moralez, \& Canto, 2019). En Europa el sector industrial es la principal prioridad para el 2020, y su proyección es incrementar su participación de $15.1 \%$ a $20 \%$. En lo que respecta a Asia Oriental, el país con más inclinación hacia el sector industrial es Japón que ocupa 25 \% de la mano de obra del sector. Por su parte los países de Latinoamérica con mayor crecimiento en el sector de producción industrial son Ecuador (10.1\%), Paraguay (6.5\%) y Argentina (6.3\%). En contraste, en el 2013 Uruguay disminuyó en $1 \%$ la producción industrial (Benítez, Martínez, Margalina, \& Valencia, 2020). La industria del calzado en Ecuador ha experimentado un importante crecimiento desde el 2009 (Romero, 2018).

En el Ecuador las pequeñas industrias del calzado artesanal constituyen un motor de crecimiento económico al ser una de las principales actividades que generan empleo (Erazo \& Narváez, 2020). En la actualidad, el sector del calzado ecuatoriano está compuesto por 5800 empresas de origen familiar, varias de ellas artesanales, que ya están en manos de las segundas y terceras generaciones (Arévalo, 2021). El sector manufactura está considerado como uno de los más importantes dentro de los aportantes al crecimiento de la economía en el Ecuador pues contribuyó en el año 2011 con un $12.8 \%$ al PIB real y un $14.78 \%$ a la generación de empleo de la concentración de mano de obra nacional, empleando hasta 100 mil trabajadores (Calderón, Dini, \& Stumpo, 2016).

En el 2018 la industria del calzado ecuatoriano fabricó un promedio de 31 millones de pares de zapatos, y se considera como una de las manufacturas más importantes del país por su aporte económico (Campaña, 2021). En el país hay 5800 establecimientos registrados como fabricantes de zapatos, la mayoría ubicados en Tungurahua que representan el $80 \%$ de la producción, seguidos por los productores de Guayas, Azuay, Pichincha, Los Ríos y otras provincias (Romero, 2018).El desarrollo de la industria manufacturera juega un rol muy relevante en cuanto a la producción y productividad nacional que se ha basado principalmente en el sector agrícola y petrolero; sin embargo, en la actualidad la producción se encuentra tomando un rumbo diferente al contribuir de manera positiva y progresiva con la generación de productos con mayor valor agregado (Camino-Mogro, Armijos-Bravo, \& Cornejo-Marcos, 2018).

La productividad de las industrias de calzado del Ecuador es un indicador ligado a la productividad del país. (Saltos, Jiménez \& López, 2017). La productividad es un indicador de producción que depende de factores internos como las instalaciones, equipos, insumos, mano de obra; y también de factores externos, como las entregas de los proveedores, políticas comerciales y tributarias, entre otras (Mayorga, Ruiz, Mantilla \& Moyolema, 2015). El índice de producción de la industria manufacturera conocido como IPI-M, mide el comportamiento, en la coyuntura nacional ecuatoriana de la producción generada en el corto plazo. Se determina a partir del valor de ventas y la variación de existencias, de los bienes producidos en cada uno de los establecimientos manufactureros en el Ecuador. (Instituto Nacional de Estadísticas y Censos - INEC, 2019). 
La productividad está relacionada con la capacidad de un bien para satisfacer plenamente las necesidades de los consumidores (calidad) y para adaptarse a los sistemas de producción de las organizaciones. Así, el diseño de un producto y la calidad con que es ofrecido determinarán en gran medida el valor que los grupos de interés están dispuestos a pagar por él (Fontalvo-Herrera, Hoz-Granadillo \& Morelos-Gómez, 2018). Los niveles de productividad se ven influenciados por los factores que conforman el proceso productivo; estos factores son la mano de obra, la materia prima empleada, el ambiente laboral y la maquinaria equipos e instalaciones que ayudan a transformar la materia prima en producto terminado (Render \& Heizer, 2017).

En el presente trabajo se muestran los resultados del análisis situacional de las empresas productoras de botas de seguridad industrial en el Ecuador, análisis basado en parámetros como la productividad, comportamiento financiero y los niveles de calidad del producto para esto se muestran parámetros de los procesos evaluados en sitio y en condiciones reales de operación, se incluyen características financieras de las empresas y la calidad del producto será inferida través de los resultados de ensayos de laboratorio a los que se somete el producto de acuerdo a lo que establece la norma INEN - ISO 20346:2014 del Servicio Ecuatoriano de Normalización.

\section{Metodología}

La metodología se desarrolló siguiendo las siguientes etapas: 1) Selección de la muestra. 2) Diagnóstico situacional de las empresas productoras de calzado de seguridad. 3) Diagnóstico financiero de las empresas productoras. 4) Evaluación del proceso de producción de calzado de seguridad en base a los elementos del proceso productivo. 5) Evaluación de la Calidad del calzado de seguridad a través de ensayos.

\subsection{Población y muestra}

De acuerdo a Espinoza (2017) en el Ecuador los productores de calzado de seguridad industrial certificado se encuentran ubicados en Ambato, Quito y Cuenca. En el Ecuador existe un total de 13 empresas productoras de calzado de seguridad industrial, de las 13 empresas 7 ofrecen productos sometidos a ensayos de laboratorio bajo la norma INEN - ISO 20346: 2014 (Revelo, 2016; Espinoza, 2017).

Se inició con la selección de las empresas para el estudio, partiendo de una población de cinco empresas que fabrican botas de seguridad industrial certificadas, tres de las cuales se encuentran ubicadas en la provincia de Pichincha (Quito), una está en la Provincia de Tungurahua (Ambato) y una en la provincia del Azuay (Cuenca) (Chimarro, Mora \& Rueda, 2020). Las 5 empresas representan el 71,4\% de las que si ensayan sus productos bajo la norma considerada. Por otra parte, las 5 empresas si contaban con información de sus procesos, registros de ensayos de calidad del producto y permitieron acceder a sus instalaciones.

\subsection{Análisis situacional de las empresas que producen botas de Seguridad Industrial. (as)}

A fin de establecer el escenario general en el que están las empresas se realizó un análisis situacional (as) de las mismas considerando los siguientes factores: Número de 
trabajadores (as-f1), tipo de empresa (as-f2), nivel de estudio de los trabajadores (as-f3), tiempo de permanencia de la empresa en el mercado (as-f4). Los factores mencionados permitieron obtener el diagnóstico requerido a continuación se explica uno a uno el porqué de su inclusión en el diagnóstico. En cuanto a (as-f1) tipos de empresa (si es familiar o no lo es), este factor incide en la búsqueda de supervivencia en el mercado es superior en las empresas familiares. Kellermans, Eddleston, Barnett \& Pearson (2008) menciona que la supervivencia de la empresa familiar es un asunto importante para las familias ya que su principal objetivo es construir un legado duradero para sus descendientes y que la empresa continúe activa a través de las generaciones, lo cual sugiere que están potencialmente abocadas a la maximización del valor a largo plazo. El segundo factor es el número de trabajadores, hecho que podría señalar que el tamaño de empleo, las ventas y la cantidad de dinero gastado en comprar materias primas o mercancías para su reventa están positivamente correlacionadas (Cotler, 2015). Por otra parte, en cuanto al número de trabajadores (as-f2) es importante determinar, entre otras variables el nivel de empleo (número de trabajadores) para la clasificación de las micro, pequeña y mediana empresa, puesto que las instituciones gubernamentales que diseñan e implementan políticas públicas se basan en estos indicadores (Chávez, Campuzano, \& Betancpurt, 2018). El factor nivel de estudio de los trabajadores (as-f3) es fundamental en el análisis situacional de las organizaciones debido a que en la medida que la gestión del talento se centra en su formación, es decir, en la adquisición de conocimientos que le posibilitan a los colaboradores desarrollar competencias para desempeñar mejor su trabajo, incrementando su productividad y su motivación, siendo una evidente ventaja competitiva para las organizaciones en la medida que la gestión del talento se centra en un factor que indica que el conocimiento ahora es básico y el mejor desafío está en lograr su productividad (AgudeloOrrego, 2019). El cuarto factor de diagnóstico (as-f4) tiempo de permanencia de la empresa en el mercado. El crecimiento de la Empresa está relacionado con la supervivencia (permanencia en el mercado) y además incidiendo positivamente en ella (Morales-Ramos, Morales-Ramos \& Valle-Álvarez, 2017).

Con los factores mencionados se procedió a estructurar una encuesta dirigida a los representantes de las empresas fabricantes de botas de seguridad. Considerando que la investigación es de carácter exploratorio y de naturaleza cualitativa se aplicó la encuesta que fue validada por los directivos de las empresas y los responsables de los procesos de producción aplicando la técnica de Delphi; los resultados de la validación a través de la técnica de Delphi permiten comprobar la validez y confiabilidad de un instrumento de investigación (López-Gómez, 2018). La encuesta no fue sometida a validación estadística debido a que antes de aplicar la encuesta definitiva se aplicaron dos encuestas piloto que fueron sometidas a juicio de los expertos de las empresas (jefes de producción, gerentes, encargados de investigación y desarrollo), la experticia de los mismos se verificó a través de años de experiencia, nivel de formación y experiencia en proyectos de investigación y desarrollo empresarial. En la encuesta se formularon preguntas como las siguientes: a) ¿Cuál es el tipo de Empresa: familiar o no familiar? b) ¿Qué tiempo de permanencia tiene en el mercado? c) ¿Cuántos trabajadores tiene la Empresa? d) ¿Cuál es el nivel de estudio del talento humano de su empresa?

El diagnóstico situacional se puede observar en la figura 1. 


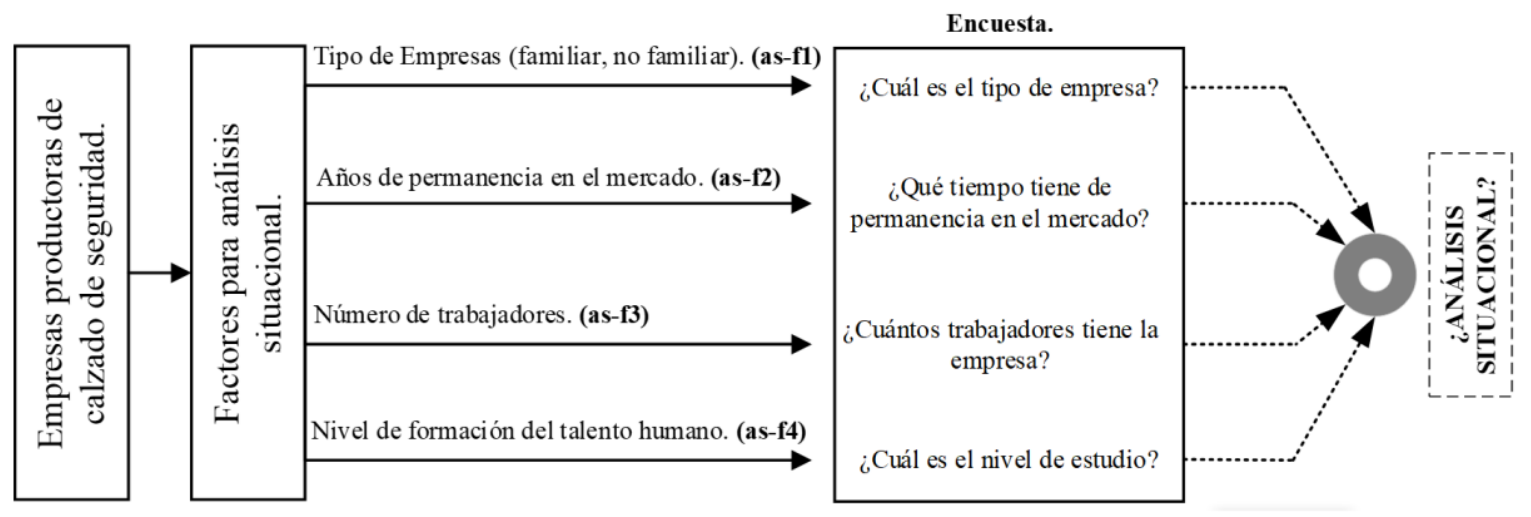

Figura 1: Análisis situacional de las empresas.

\subsection{Análisis financiero de las empresas (af).}

Para analizar el escenario financiero de las empresas se consideró los siguientes factores: volumen de gastos semanales (af-f1), obligado a llevar contabilidad o no (af-f2), precio de venta de cada par de botas (af-f3), tipo de financiamiento: propio o ajeno (df-f4). Con la ayuda de estos factores se generó un diagnóstico del desempeño financiero empresarial. En este sentido el volumen de gastos semanales (af-f1), de acuerdo a la normatividad internacional no considera cuestiones más importantes que los resultados obtenidos por la diferencia entre los ingresos y los gastos para medir el desempeño de las empresas (Adam, 2005). En cuanto al factor "obligado a llevar contabilidad o no, Palacios (2017) menciona que "La contabilidad es una parte esencial en una empresa. La contabilidad permite ver la realidad de su negocio, e incluso pueden tomar decisiones para aprovechar incentivos y beneficios tributarios. Del mismo modo de acuerdo a Torgler \& Schnaider (2007), "la informalidad es un fenómeno que reconoce múltiples causas y genera distintas consecuencias. Una de estas causas en muchos casos, se relaciona con el nivel y la estructura del sistema tributario mediante el efecto que los impuestos ejercen sobre las decisiones racionales de tipo individual para pertenecer al sector formal de la economía, en tanto estos sean percibidos como un costo necesario para su logro". El factor precio de ventas (af-f3) también se considera para el diagnóstico, Bernal (2019) considera que "los factores internos y externos que inciden en el crecimiento empresarial son: edad, tamaño, perfil del propietario, motivación, gestión del conocimiento, estrategias de crecimiento: ingreso por ventas, incremento de activos, reinversión de utilidades, aumento de participación del mercado incremento del activo total, volumen de ventas, ingresos, costos, financiación, número de empleados, inversión neta, liderazgo y cultura empresarial". De lo anterior puede verse entonces que el ingreso por ventas (af-3) producto de la venta del producto "botas de seguridad" también permite contribuir al diagnóstico financiero empresarial.

El factor (af-f4) tipo de financiamiento (endeudamiento o no), determina la situación financiera de la organización. Para Córdova, Duque \& González (2018) “Los empleados de las organizaciones generadoras de plazas de trabajo querrán conocer acerca de la estabilidad y supervivencia de estas, ya que su rentabilidad garantiza la capacidad de que la empresa cumpla con sus obligaciones sobre sueldos, beneficios, seguridad, salud laboral, entre otras, por lo que la falta de liquidez o altos niveles de endeudamiento pudieran ocasionar que las 
empresas no cumplan con estas obligaciones". La relación entre la responsabilidad social y el endeudamiento tiene dos puntos de vista: el primero que sostiene una relación directa entre las empresas con mayor índice de endeudamiento y un alto grado de responsabilidad social, al tener mayor acceso a la obtención de financiamiento externo y al estar dispuestas a cumplir con las expectativas de sus acreedores.

Con los factores mencionados se procedió a estructurar una encuesta dirigida a los fabricantes de botas de seguridad, en la encuesta se formularon preguntas como las siguientes 1) ¿Cuál es el volumen de gastos semanales? 2) Su organización está o no obligada a llevar contabilidad? 3) Cuál es el precio promedio de las botas de seguridad que comercializa? 4) Cómo financia las operaciones de su organización tiene deudas o no y en qué porcentaje. En la figura 2 se ilustra la metodología seguida para realizar el análisis financiero de las empresas.

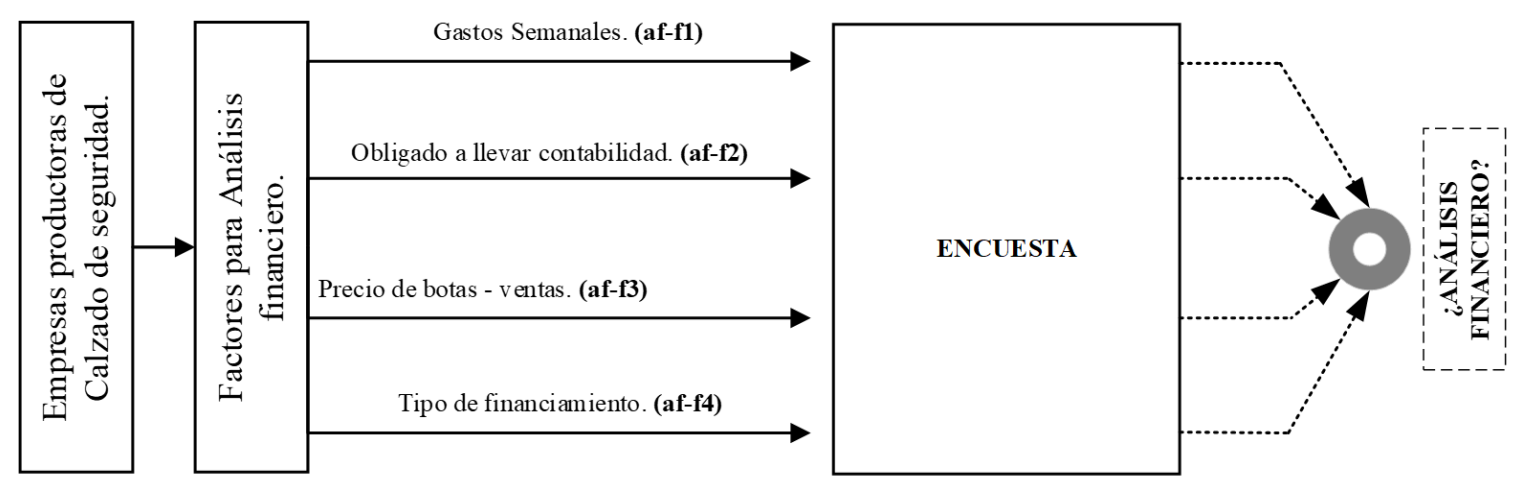

Figura 2: Análisis financiero de las empresas.

\subsection{Evaluación del proceso de producción}

De acuerdo al Ministerio de Industrias y Productividad - MIPRO (2016), "las botas de seguridad son un tipo calzado de protección individual que se comercializa en el Ecuador, sean estos importados o de producción nacional. El calzado de seguridad es el calzado que incorpora elementos para proteger al usuario de las lesiones que le pueden ocasionar los accidentes". El presente estudio se centra en el calzado de seguridad que debe cumplir los requisitos básicos establecidos en la norma INEN - ISO 20346: 2014 vigente o sus equivalentes.

Las botas de seguridad están conformadas por: la suela que contiene la plantilla interior, el capellado y la punta; dicha estructura se puede ver en la figura 3.

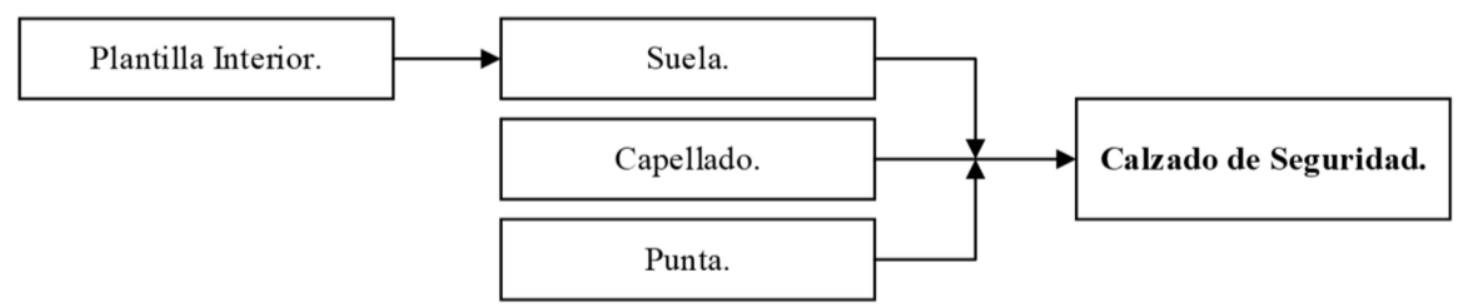

Figura 3: Estructura del producto "botas de seguridad".

El proceso de producción del calzado de seguridad se ilustra en la figura 4 que se inicia con la etapa (i) la compra de materiales e insumos por parte de un jefe de compras, (ii) el jefe de producción ejecuta la planificación de la producción, (iii) a continuación se hace la 
recepción de materia prima e insumos, en la etapa cuatro (iv) se da el corte de cuero y forro, la etapa cinco (v) es el aparado, a continuación viene el preparado de punteras, contrafuertes y preformados (vi), en la etapa de preparado también está el armado, ya; en la etapa siete (vii) se da el montaje etapa que contiene sub etapas como el envejecimiento, el cardado, el pegado, el prensado, la estabilización molecular y el cosido. La última etapa del proceso productivo es el empacado (viii). El proceso descrito se puede visualizar en la siguiente figura:

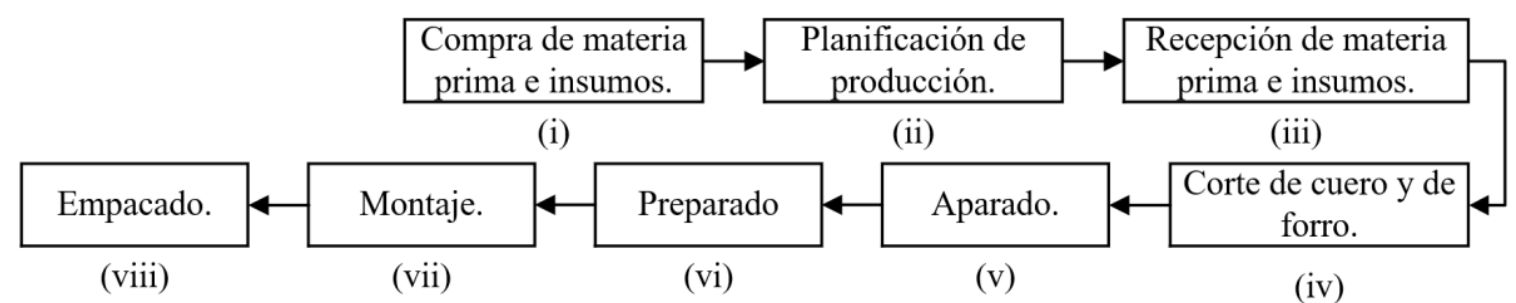

Figura 4: Proceso de producción de botas de seguridad

Para establecer los factores del proceso productivo que inciden en la productividad se generó un constructo que relaciona la productividad de las organizaciones en función de dos dimensiones: la dimensión humana y la dimensión misma del proceso productivo. La dimensión del proceso contiene subdimensiones como son la materia prima (MP), la mano de obra (MO), el método de trabajo (MT), el medio ambiente (MA) y la maquinaria (MAq) (Jaimes, Luzardo \& Rojas, 2018). Se aplicó un enfoque sistémico en donde los factores mencionados pueden informar sobre los niveles de productividad. La productividad es un indicador que mide el funcionamiento y evolución de un sistema productivo. Para nuestro caso se consideraron las dimensiones citadas y pueden ser entendidas como factores que influyen en la productividad empresarial pues se constituyen en elementos fundamentales del proceso. Cada factor considerado en el estudio puede integrarse en un solo indicador denominado productividad total que permita medir el comportamiento del sistema (Render \& Heizer, 2017).

\subsubsection{El factor Maquinaria (MAq)}

A través de visitas de campo se procedió a identificar los equipos en las áreas productivas. La “Disponibilidad de equipos" permitió evaluar al factor maquinaria (MAq), para obtener datos que permitan calcular este indicador se ejecutó revisión de documentos como registros de fallas de maquinaria, bitácoras de producción y para validar los datos obtenidos se aplicaron entrevistas a los responsables de mantenimiento de las empresas en estudio. A fin de garantizar la representatividad del estudio se seleccionó a una de las cinco empresas a la que le denominaremos empresa (1), está empresa se seleccionó aplicando criterios como: apertura a brindar información, contar con la documentación necesaria, los registros de fallas son completos y coherentes y, la posibilidad de verificar en sitio los datos recogidos. Las máquinas incluidas en el estudio de muestran en la siguiente tabla: 
Tabla 1: Máquinas para el proceso de producción de botas de seguridad

\begin{tabular}{|c|c|c|c|c|c|c|c|c|c|c|c|c|c|c|c|c|c|c|c|c|}
\hline \multicolumn{21}{|c|}{ Listado de máquinas y su codificación. } \\
\hline 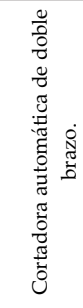 & 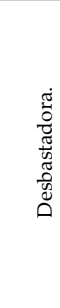 & 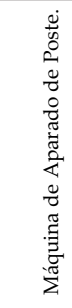 & 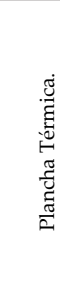 & 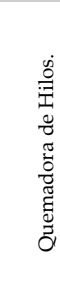 & 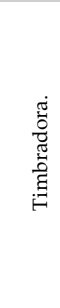 & $\begin{array}{l}\frac{\pi}{0} \\
\frac{\pi}{0} \\
\frac{\pi}{0} \\
\bar{\Xi}\end{array}$ & 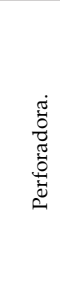 & 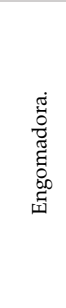 & 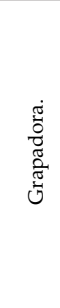 & 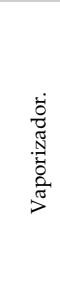 & 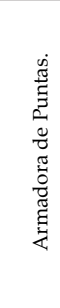 & 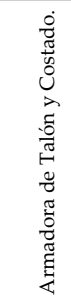 & $\begin{array}{l}\text { : } \\
\text { : }\end{array}$ & 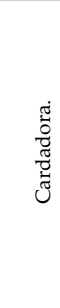 & 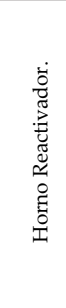 & 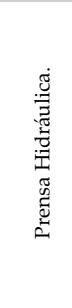 & 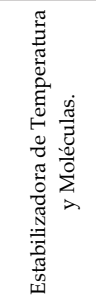 & 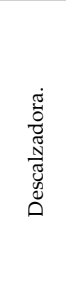 & 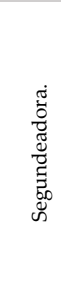 & 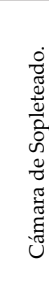 \\
\hline CADB & DB & MAP & PT & $\mathrm{QH}$ & ТВ & OJ & PR & EG & GP & VP & $\mathrm{AP}$ & ATC & $\mathrm{HC}$ & $C D$ & HR & $\mathrm{PH}$ & ETM & DS & SD & CS \\
\hline-1 & -2 & -3 & -4 & -5 & -6 & -7 & -8 & -9 & -10 & -11 & -12 & -13 & -14 & -15 & -16 & -17 & -18 & -19 & -20 & -21 \\
\hline
\end{tabular}

La disponibilidad (Dis.) puede ser definida como la proporción de tiempo (puede estar en porcentaje o no) en que una máquina, un quipo o una instalación está en condiciones de ser usada y es igual al total de horas consideradas (HT) menos las horas perdidas por mantenimiento (HM) sobre las horas totales por $100 \%$ si se quiere expresar en porcentaje (Flores, Medina, Vargas, Remache-Vinueza., 2020). La disponibilidad se calculó aplicando la ecuación (1)

$$
\text { Dis }=\frac{\mathrm{HT}-\mathrm{HM}}{\mathrm{HT}} * 100 \%
$$

\subsubsection{Los Métodos de trabajo (MT)}

Los métodos de trabajo determinan los "procedimientos de ejecución" entendiendo por tal, la forma como el ejecutante realiza la labor asignada. Esta consideración de la forma de trabajar para fijar una manera tal que asegure resultados mejores (Palacios, 2017). Un procedimiento es la forma como se ejecuta un proceso, de ahí que evaluar los métodos de trabajo es evaluar la forma como se organiza y ejecuta el proceso. En esta etapa se procedió a ver la manera como los trabajadores organizaban su trabajo, cómo se designaban los recursos y las funciones en las instalaciones, empleando fichas de observación se registró la ejecución de los procesos y las herramientas de organización y principios de dirección que se empleaban en los puestos de trabajo. En la tabla 2 se observa que las herramientas de organización son: diagramas, perfiles de puesto y manuales de organización mientras que para la etapa de dirección se evaluó la manera de comunicar las órdenes y disposiciones, la forma de supervisar las labores y los niveles de liderazgo mostrados en las áreas de proceso.

\begin{tabular}{cc} 
Tabla 2: Herramientas de organización y principios de dirección \\
\hline Organización & Dirección \\
\hline Organigrama. & Integración. \\
Diagramas de Flujo. & Liderazgo. \\
Análisis y descripción & Motivación. \\
de puestos. & Comunicación. \\
Manuales de & Supervisión de \\
organización. & resultados. \\
Perfiles de puestos y & Toma de decisiones. \\
cargos. & \\
\hline
\end{tabular}




\subsubsection{Medio ambiente laboral (MA).}

Para continuar con la evaluación del proceso productivo y los factores que influyen en el mismo se procedió a evaluar el ambiente laboral o ambiente organizacional, para esto se aplicaron encuestas a los trabajadores de planta es decir aquellos que están en contacto directo con el producto elaborado "botas de seguridad". A través de una serie de preguntas se puede medir las aseveraciones en torno a las motivaciones, decisiones y acciones en una organización lucrativa. Incluye cuatro opciones de respuesta que van desde "nunca" hasta "siempre". Un grupo de reactivos configuran el factor reconocimiento laboral y otro grupo al factor "crecimiento personal", la percepción es un proceso psicológico que se complementa con procesos actitudinales, intencionales, evaluativos, motivacionales y conductuales (Cruz, 2010).

\subsubsection{Materia prima (MP).}

La materia prima como factor que incide en los niveles de productividad fue evaluada empleando el indicador "eficiencia de uso de materia prima" indicador que se consigue al dividir la cantidad de materia prima estándar (MPE) o programada para la cantidad de materia usada o empleada (MPU). Este indicador puede informar no solo de la calidad de la materia prima sino también de la forma como esta se emplea por el trabajador. El término eficiencia se emplea para relacionar los esfuerzos frente a los resultados que se obtengan. A mayores resultados, mayor eficiencia. Si se obtiene mejores resultados con el menor gasto de recursos o menores esfuerzos, se habrá incrementado la eficiencia (García, Cazallo, Barragán, Mercado, Olarte \& Meza, 2019). Para calcular el indicador eficiencia de uso de materia prima se aplicó la ecuación (2):

$$
\text { Eficacia de uso de MP }=\frac{\mathrm{MPE}}{\mathrm{MPU}} * 100 \%
$$

A fin de obtener los datos y calcular el indicador citado se tomaron como muestra órdenes de producción y reportes de producción para un total de 120 pares de botas. Es importante aclarar que para el cálculo se consideró solo la materia prima (cuero hidrofugado y cuero de refuerzo) que se emplean para fabricar las "botas de seguridad".

\subsubsection{Mano de obra (MO)}

El factor mano de obra como elemento del proceso productivo fue evaluado en función de su productividad. La productividad de la mano de obra es una medida de la eficiencia con la que los recursos humanos han realizado su labor para alcanzar los resultados planificados. Los recursos humanos tienen un alto nivel de relevancia en el mejoramiento de la productividad (Bohórquez, Caro, \& Morales, 2017).

Los datos para calcular la productividad parcial (de la mano de obra) se obtuvieron de reportes de producción de 12 meses considerando datos de: Productos obtenidos por día (pares de botas de seguridad), productos por semana, productos por mes y finalmente productos obtenidos en un año de trabajo (Unidades producidas en un año: UP); los productos son las salidas del proceso. A fin de obtener los valores del recurso considerado (para este caso horas hombre (hh) se tomaron los datos de (hh) del mismo periodo de estudio. 
La productividad de mano de obra (MO) se obtuvo aplicando la ecuación (3) Al cálculo de productividad de mano de obra se lo conoce también como productividad de un solo factor (Render \& Heizer, 2017).

$$
\text { Productividad de } \mathrm{MO}=\frac{\mathrm{uP}}{\mathrm{hh}}
$$

\subsection{La calidad del calzado de seguridad}

Para complementar el estudio se procedió a evaluar la calidad de las botas de seguridad de acuerdo a las normas que el producto (botas de seguridad) debe cumplir antes de ingresar al mercado. La Organización Internacional de Estandarización (ISO), ha establecido normas que definen las características de este producto. Las botas antes de salir al mercado deben cumplir lo que establece la Norma Técnica Ecuatoriana (NTE) INEN ISO 20346 cuya versión es del año 2014. (Ministerio de Industrias y productividad (MIPRO), 2016). De las revisiones efectuadas se encontró que la norma presenta requisitos básicos y opcionales que debe cumplir el calzado de seguridad, e incluye pruebas o ensayos que garanticen la protección frente a riesgos mecánicos, resistencia al deslizamiento, patrones de comportamiento ergonómico y riesgos térmicos. Se observó que el producto y sus componentes son sometidos a distintos ensayos los mismos que están en función del parámetro a verificar y el componente del producto.

Se encontró que a los distintos componentes se les aplica ensayos de acuerdo al siguiente detalle:

- Al cuero se le realizan ensayos de tracción (NTE INEN - ISO 3376; NTE INEN 1061), resistencia al agua \% (NTE INEN ISO 5404), porcentaje de alargamiento, flexión y absorción. De acuerdo a la NTE INEN 1926; 6.2

- A la suela se le realizan ensayos de dureza flexión y resistencia a la abrasión (NTE INEN ISO 20871; métodos de referencia ISO 4649), de acuerdo a la Norma Técnica Ecuatoriana, NTE INEN 1813.

- Los elementos metálicos que contienen las botas de seguridad se le realizan ensayos de resistencia a la corrosión de acuerdo a la NTE INEN ISO 20344: 2014

- A la puntera se le realizan ensayos de resistencia al impacto (NTE INEN ISO 20344: 2014) y resistencia a la compresión de acuerdo a la Norma Técnica Ecuatoriana, NTE NEN 1922.

- A los hilos se le realizan ensayos de resistencia de las costuras para probar su calidad de unión de acuerdo a NTE INEN 1920.

Los datos anteriores fueron obtenidos de registros de los laboratorios del Servicio Ecuatoriano de Normalización desde el año 2014 hasta el año 2020 su correspondencia fue verificada con los respectivos catálogos (Servicio Ecuatoriano de Normalización - INEN, 2020).

\section{Resultados}

3.1. Situación de las empresas que producen botas de Seguridad Industrial. (as) 
Los resultados del análisis situacional de las empresas que producen calzado de seguridad industrial se muestran en la tabla 3.

Tabla 3: Las empresas que producen botas de seguridad

\begin{tabular}{|c|c|c|c|c|c|c|}
\hline \\
\hline \# & Ubicación & $\begin{array}{l}\text { Tipo de } \\
\text { empresa }\end{array}$ & $\begin{array}{c}\text { Años de } \\
\text { permanencia } \\
\text { en el mercado }\end{array}$ & Actividad económica & $\begin{array}{l}\text { Número de } \\
\text { trabajadores }\end{array}$ & $\begin{array}{c}\text { Nivel de } \\
\text { formación de los } \\
\text { trabajadores }\end{array}$ \\
\hline 1 & Quito & familiar & 49 & $\begin{array}{c}\text { Fabricación y } \\
\text { comercialización }\end{array}$ & 40 a 85 & Básica o primaria \\
\hline 2 & Quito & familiar & 26 & $\begin{array}{l}\text { Fabricación, distribución } \\
\text { y comercialización }\end{array}$ & 7 a 32 & $\begin{array}{l}\text { Varias (incluye } \\
\text { básica o primaria) }\end{array}$ \\
\hline 3 & Quito & familiar & 31 & $\begin{array}{l}\text { Fabricación y } \\
\text { distribución }\end{array}$ & 7 a 35 & $\begin{array}{l}\text { Varias (incluye } \\
\text { básica o primaria) }\end{array}$ \\
\hline 4 & Ambato & $\begin{array}{c}\text { no } \\
\text { familiar }\end{array}$ & 30 & $\begin{array}{c}\text { Fabricación, distribución } \\
\text { y comercialización }\end{array}$ & 32 a 70 & $\begin{array}{l}\text { Varias (incluye } \\
\text { básica o primaria) }\end{array}$ \\
\hline 5 & Cuenca & familiar & 42 & $\begin{array}{c}\text { Fabricación y } \\
\text { comercialización }\end{array}$ & 7 a 32 & Secundaria \\
\hline
\end{tabular}

Según la tabla 3, el 60 \% (tres) de las empresas estudiadas están en la ciudad en Quito, una de ellas (20\%) en Cuenca y una (20\%) en Ambato. Como ya se dijo en la sección de metodología estas empresas se consideran representativas por la cantidad de producción, su presencia en el mercado, y por la calidad del mismo, de acuerdo a Revelo (2016) estas comercializan el $42 \%$ de las botas de seguridad industrial en el Ecuador. La tabla 3 nos muestra que de las empresas consideradas el $80 \%$ (cuatro empresas) son familiares y solo una de ellas no lo es. En cuanto al tamaño de acuerdo al número de trabajadores tres de ellas (el 60\%) son "pequeñas empresas", clasificación que corresponde con lo que establece la Comisión para América Latina (Comisión Económica para América Latina y el Caribe CEPAL, 2020) pues tiene entre 7 a 32 trabajadores (la CEPAL determina que son pequeñas empresas las que tienen entre 5 y 49 trabajadores). Por otra parte, dos (el 40\%) de las cinco empresas son medianas pues tienen menos de 250 trabajadores (para la CEPAL las empresas medianas son aquellas que tienen entre 50 a 250 trabajadores). Finalmente, del análisis situacional se desprende que todas las empresas cuentan con trabajadores cuyo nivel de formación es de nivel básico o primario.

\subsection{Situación financiera (sf) de las empresas productoras de botas de Seguridad Industrial}

Las encuestas aplicadas y la revisión de la realidad de las empresas productoras de calzado de seguridad mostraron que para tres de ellas es decir el 60\% el volumen de gastos semanales va entre 350 y 1600 dólares semanales lo que puede entenderse como un flujo bajo de recursos financieros que sostienen sus operaciones; y los dos restantes tiene gastos superiores a los 1300 dólares semanales y derivado de esto tres empresas están obligadas a llevar contabilidad mientras que las dos restantes no lo están.

Tabla 4: Situación financiera de las empresas productoras de botas de seguridad

\begin{tabular}{ccccc}
\hline Empresa & $\begin{array}{c}\text { Gastos semanales } \\
(\$)\end{array}$ & $\begin{array}{c}\text { Obligado a llevar } \\
\text { contabilidad }\end{array}$ & $\begin{array}{c}\text { Precio de } \\
\text { venta }- \text { botas } \\
(\$)\end{array}$ & $\begin{array}{c}\text { Tipo de } \\
\text { financiamiento }\end{array}$ \\
\hline 1 & $>1300$ & si & $\$ 55.00$ & Propio y privado \\
2 & {$[400--700]$} & si & $\$ 100.00$ & Propio \\
3 & {$[350--800]$} & no & $\$ 42.00$ & Propio \\
4 & {$[820--1600]$} & si & $\$ 50.50$ & Privado \\
5 & $>1500$ & si & $\$ 70.00$ & Propio \\
\hline
\end{tabular}


Se estableció que el precio del par de botas de seguridad va desde los 42 dólares a los 100 dólares, precios que son en fábrica. Finalmente se determinó que tres empresas tienen capital propio es decir se auto financian y dos de ellas han adquirido deudas para poder seguir funcionando. Las diferencias de precio del producto entre una y otra empresa determina los niveles de ingreso y la calidad del producto ofrecido.

\subsection{El estado de los procesos de producción.}

\subsubsection{El factor Maquinaria (MAq.)}

Los cálculos mostraron que la disponibilidad de maquinaria va desde el $98.95 \%$ lo cual para este tipo de organizaciones es adecuado por sus regímenes de trabajo (no laboran las 24 horas al día) pues determina que los procesos productivos no se detengan por falla de mantenimiento. El valor de $98.5 \%$ determina que del 100\% del tiempo que se requiere que las máquinas estén listas para ser usadas menos del $2 \%$ no están operativas por problemas de mantenimiento y el $98 \%$ están listas para ser usadas. Los resúmenes de valores de disponibilidad se pueden ver en la figura 5.

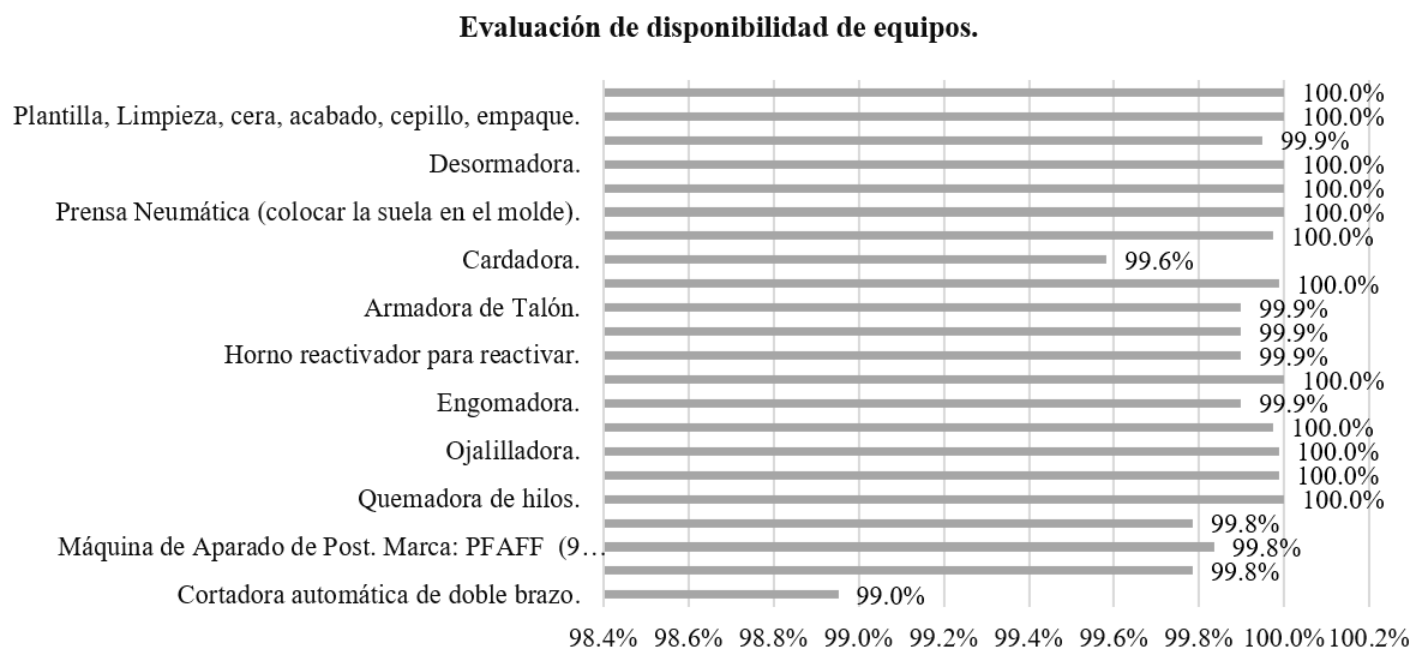

Figura 5: Disponibilidad de equipos y maquinaria.

\subsubsection{Los métodos de trabajo (MT)}

Se encontró que en las empresas cuentan con organigramas estructurales y funcionales lo que determina que las funciones, responsabilidades, líneas y canales de mando estén definidas, así mismo hay descripción de puestos; sin embargo, las empresas no tienen procesos diagramados lo que determina variaciones al momento de ejecutar las tareas, por otro lado, los perfiles de puesto no están definidos o están a medias. Se observó que hay liderazgo en los mandos medios y altos y que hay buena comunicación desde las cabezas de las áreas, se evidenció que las órdenes y disposiciones son claras y se cumplen de manera eficiente; sin embargo, las formas de supervisión y control de las labores no son adecuadas esto hace que muchas veces las decisiones que se toman no se compadecen con las realidades y problemas que se enfrentan. 
Tabla 5: Evaluación de los métodos de trabajo

\begin{tabular}{|c|c|c|c|c|c|}
\hline Organización & C & $\mathrm{NC}$ & Dirección & C & $\mathrm{NC}$ \\
\hline Organigrama. & $X$ & & Integración. & & $X$ \\
\hline Diagramas de Flujo. & & $x$ & Liderazgo. & $X$ & \\
\hline Análisis y descripción & $X$ & & Motivación. & & $X$ \\
\hline de puestos. & & & Comunicación. & $x$ & \\
\hline $\begin{array}{l}\text { Manuales de } \\
\text { organización. }\end{array}$ & & $X$ & $\begin{array}{l}\text { Supervisión de } \\
\text { resultados. }\end{array}$ & & $X$ \\
\hline $\begin{array}{l}\text { Perfiles de puestos y } \\
\text { cargos. }\end{array}$ & & $x$ & Toma de decisiones. & & $x$ \\
\hline
\end{tabular}

\subsubsection{El factor medio ambiente (MA).}

El cuestionario para evaluar las condiciones de trabajo fue aplicado al personal operativo, la escala de valoración tenía 4 niveles: nunca (10\%), a veces (20\%), casi siempre $(30 \%)$, siempre $(40 \%)$, de esto se evaluaron 22 factores que se muestran en la figura 6 . Los reactivos se validaron empleando el método de Delphi.

Se encontró que hay aspectos positivos o que están en valores adecuados como las condiciones físicas del puesto (f1), el ambiente de trabajo es adecuado pues el trato por parte de supervisores y jefes inmediatos es adecuado (f2), las relaciones interpersonales entre compañeros también son adecuadas (f6), otros que están en esta escala (40\% siempre) son los beneficios a los trabajadores, la participación en actividades recreativas y culturales (f18). Los factores peor valorados (30\% casi siempre) fueron el trabajo en equipo (f5), la comunicación dentro del equipo de trabajo (f7), los planes y acciones de mejora (f11), la disponibilidad de recursos (f21) y la valoración del trabajador (f22).

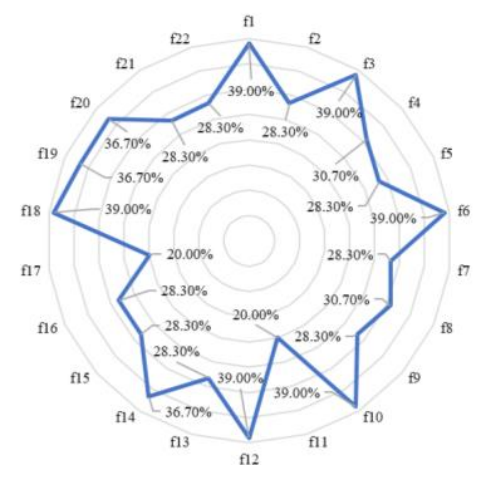

\begin{tabular}{clcl}
\hline Código. & \multicolumn{1}{c}{ Denominación. } & Código. & \multicolumn{1}{c}{ Denominación. } \\
\hline f1 & Condiciones fisicas del puesto de trabajo. & $\mathrm{f} 12$ & Beneficios a los trabajadores. \\
f2 & Tiempo para realizar el trabajo. & $\mathrm{f} 13$ & Definición de funciones. \\
f3 & Actitud del Jefe Inmediato. & $\mathrm{f} 14$ & Compromiso para apoyo en el trabajo. \\
f4 & Nivel de Satisfacción en la empresa. & $\mathrm{f} 15$ & Apoyo de Lideres. \\
f5 & Trabajo en equipo. & $\mathrm{f} 16$ & Respaldo de Lideres. \\
f6 & Ambiente de trabajo. & $\mathrm{f} 17$ & Autonomía para la toma de decisiones. \\
f7 & Comunicación dentro del grupo de trabajo. & $\mathrm{f} 18$ & Participación en actividades culturales y recreativas. \\
f8 & Tiempo para completar el trabajo. & $\mathrm{f} 19$ & Información para el desarrollo del trabajo. \\
f9 & Nivel de motivación del personal. & $\mathrm{f} 20$ & Retroalimentación de Evaluación de Desempeño. \\
f10 & Relación entre compañeros de trabajo. & $\mathrm{f} 21$ & Disponibilidad de recursos. \\
f11 & Planes y acciones de mejora. & f22 & Valoración del Trabajador. \\
\hline
\end{tabular}

Figura 6: Factores para evaluar el clima organizacional

\subsubsection{El factor materia prima (MP).}

La materia prima es cuero hidrofugado y cuero de refuerzo pues representan la mayor cantidad del producto, como ya se dijo en el apartado de metodología no se han considerado a los insumos (telas, lona, hilo, ojales, entre otros). Los datos mostraron que la eficiencia de uso del cuero hidrofugado es del 99.22\% es decir apenas hay una variación del $0.78 \%$ de lo que se programa usar. En cuanto al cuero de refuerzo la eficiencia de uso es del $100 \%$ es decir se usa lo que se programa y no se generan desperdicios, estos valores son altos gracias a la experiencia de los trabajadores y el dominio que tienen de las herramientas y elementos de trabajo. 
Tabla 6: Eficiencia de uso de materia prima

\begin{tabular}{cccccc}
\hline No. & Proceso & Materia prima & $\begin{array}{c}\text { Cantidad estándar } \\
(\mathrm{cm} 2)\end{array}$ & $\begin{array}{c}\text { Cantidad real utilizada } \\
(\mathrm{cm} 2)\end{array}$ & $\begin{array}{c}\text { Eficiencia } \\
(\%)\end{array}$ \\
\hline 1 & \multirow{2}{*}{ Corte } & Cuero hidrofugado & 142000 & 143120 & 99.2 \\
2 & & Cuero (refuerzo) & 45600 & 45600 & 100 \\
\hline
\end{tabular}

\subsubsection{El factor mano de obra (MO)}

Con la revisión de documentos como planes de producción, reportes, bitácoras se llegó encontró que se habían producido 79000 pares de zapato al año (79000 u/año) para lo que se empleó 1680 horas hombre por año (1680 hh/año). Aplicando la ecuación (2) se obtuvo una productividad de 47 pares por hora $(47 \mathrm{u} / \mathrm{h})$.

\subsection{La calidad del producto y los ensayos realizados.}

La revisión de reportes de ensayos realizados a las botas de seguridad en la empresa 1 mostró que se realizaron 81 ensayos durante el año 2020, de estos 15 fueron ensayos de resistencia la tracción de estos 2 mostraron productos fuera de especificación. Se encontraron 9 ensayos de resistencia al impacto de los que 3 muestran que el producto salió de especificación y en 6 el producto cumplió lo esperado. El ensayo que más se hizo (24 ensayos) al producto fue el de resistencia a la compresión encontrándose que solo en un (1) ensayo el producto salió fuera de norma.

Con los datos se llegó a establecer que el porcentaje de cumplimiento general de los parámetros fue de $87 \%$ y el $13 \%$ fue de incumplimiento. El ensayo más solicitado y aplicado al producto fue el ensayo de compresión (24 ensayos efectuados) y el menos requerido fue el ensayo de resistencia de las costuras (3 ensayos requeridos)

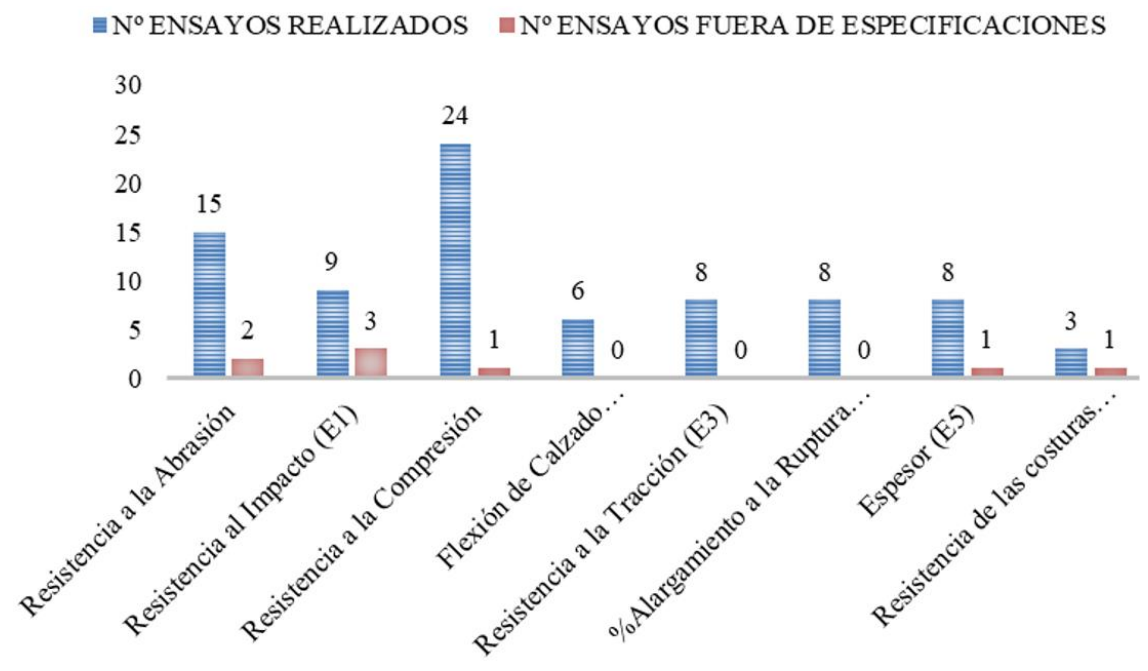

Figura 7: Ensayos realizados al producto y parámetros testeados.

La revisión de los históricos en cuanto a ensayos a las botas de seguridad desde el año 2014 hasta el año 2020 reveló que mientras en el año 2014 se efectuaron 33 ensayos y se controlaron 6 parámetros en el año 2020 se solicitaron 82 y se controlaron esos mismos 6 parámetros, esto podría verse como un crecimiento del año inicial al final, sin embargo, hubo años como el 2016 y 2017 en donde si hubo crecimiento pues se encontró que se aplicaron 237 y 245 ensayos respectivamente a 12 parámetros en el año 2016 y a 10 parámetros en el año 2017. 
Puede verse entonces que las empresas a partir del 2017 solicitaron menos ensayos pues en el 2018 solicitan 155 ensayos para 7 parámetros y en el 2019 solicitan 123 ensayos para 7 parámetros hasta llegar al 2020 en donde solicitan 82 ensayos para 6 parámetros.

\section{Discusión}

\subsection{Situación de las empresas que producen botas de Seguridad Industrial. (as)}

Describir la situación de las organizaciones a partir de ciertos factores: número de trabajadores o tamaño (as-f1), tipo de empresa: familiar o no (as-f2), escolaridad de sus empleados (as-f3), tiempo de permanencia en el mercado (as-f4), resulta una primera aproximación para comprender la realidad que enfrentan. La variable "tamaño de la empresa" busca comprobar si la dimensión de las empresas influye en la cultura, ya que cabe esperar un comportamiento estratégico distinto entre las empresas grandes, que las de menor dimensión, (Acosta \& Rodríguez, 2008). Para comprender la situación de las empresas se comparó la variable permanencia en el mercado entre las empresas que conformaron la muestra encontrándose que aquellas con más tiempo de permanencia contaban con mejores ambientes organizacionales, había personal más experimentado y con más sentido de pertenencia, contaban con personal con más experticia para desempeñar sus labores. Se pudo ver que el personal hace la diferencia en cada área de proceso. La configuración de estas variables dimensiona el talento humano (trabajadores) no como una cualidad individual, sino como una cualidad estructural de las organizaciones (MejíaGiraldo, Bravo-Castillo, \& Montoya-Serrano, 2013). Los datos encontrados reflejan que de la muestra de empresas consideradas en su mayoría son empresas familiares, todas están en la región sierra y todas son medianas empresas, de estas el 60\% de la muestra están en la provincia de Pichincha (Quito), una en Tungurahua (Ambato) 20\% y una en Azuay (Cuenca) 20\%. Se ha podido evidenciar que las empresas familiares muestran más deseos de supervivencia pues se observa sentido de pertenencia al ser parte de la tradición de sus familias. La mayoría de empresas de calzado son empresas de origen familiar, varias de ellas artesanales, que ya están en manos de las segundas y terceras generaciones (Palacios, 2017).

\subsection{Análisis financiero de las empresas productoras de botas de Seguridad Industrial}

La situación financiera del sector en estudio ha conseguido mostrar que el precio de venta del producto no determina un mayor gasto operativo, ni que el precio del producto guarde relación con el tipo de financiamiento (propio o privado de las organizaciones). Sin embargo, es claro que a mayor flujo de capital se requiere llevar contabilidad propia por las regulaciones del país. El diagnóstico financiero en el sector no ha sido fácil no todas las empresas están tan dispuestas a entregar información que permita hacer análisis más completos. Los datos mostrados no pretender reflejar íntegramente la situación financiera de las empresas pues no se han calculado indicadores como tal, se busca que, en suma, con el diagnóstico situacional hagan un complemento que muestre el estado del sector. Se observó que las variaciones en los precios de venta de los productos de una empresa a otra (estos varían de 42 a 100 dólares) inciden en los ingresos que unas y otras tienen y esto afecta a la productividad y calidad del producto ya que aquellas empresas con mayores precios de venta tenían más ingresos y más inversión en capacitación al personal, materia prima e 
insumos de mejor calidad lo que evidenció que el precio de venta del producto se relaciona con su calidad y con la productividad de la organización. Los gastos operativos destinados en cada una de las organizaciones van desde los 350 hasta 1500 dólares, estos rubros se destinan a compra de insumos del proceso, imprevistos y ajustes en compras de último momento.

\subsection{El estado de los procesos de producción de calzado de seguridad, los factores que inciden en la productividad.}

Se pudo ver que la disponibilidad de las máquinas es alta (supera el 99\%), se encontró que los procesos productivos no se detienen por paras de mantenimiento, las metas de producción pueden cumplirse según lo planificado; esto se debe a los bajos regímenes de trabajo pues ninguna de las empresas evaluadas trabaja 24 horas al día. Se encontró que los métodos de trabajo (MT) no están completamente estandarizados, existe documentación que ayuda a reducir la variabilidad de los procesos (órdenes de producción, planes de producción, diseños de productos entre otros), cuando las empresas aplican la gestión administrativa esto ayuda a que los procesos sean llevados a cabo de una manera más sencilla, la estandarización de los procesos ayuda a maximizar la productividad de los mismos (Fontalvo-Herrera et al., 2018) una adecuada estandarización mejora de los métodos de trabajo acompañada de estudios de tiempo puede incrementar la productividad (López, Alarcón \& Rocha, 2014). En América latina varios han sido los esfuerzos del sector cuero y calzado para medir sus niveles de productividad, por ejemplo, en Colombia de acuerdo a Bonilla \& Mayorga (2013), dentro de los factores que han incidido en el mejoramiento de la productividad de las empresas de este sector, se pueden mencionar la estandarización de los procesos, la capacitación al personal, la difusión del conocimiento, al interior de las organizaciones puede incidir en la calidad del producto.

\section{Conclusiones}

Tanto los análisis situacional y financiero de las organizaciones que producen botas de seguridad permitieron comprender la realidad del sector en estudio desde la arista "entorno" y desde la arista de lo "económico". Conjugar las dos aristas mencionadas permitió tener un conocimiento superior de la situación que enfrenta este sector productivo. Las empresas cuentan con talento humano experimentado (se observó personal de 16 a 25 años de experiencia en las empresas) que influye en la calidad del producto y la productividad empresarial de forma decisiva. En los recorridos se pudo observar cómo los trabajadores manipulan las máquinas de forma casi perfecta, no desperdician la materia prima (la eficiencia de uso de materia prima tiene valores del 99,22\%). Los factores empleados para el diagnóstico mostraron que no siempre es fácil evaluarlos por la complejidad para obtener los datos en la fuente misma (la evaluación del clima organizacional mostró que la resistencia al cambio del personal es evidente, los factores planes y acciones de mejora (f11), trabajo en equipo (f5), autonomía para la toma de decisiones (f17) fueron los menos puntuados) Aunque la muestra y los parámetros incluidos en los análisis son representativos puede haber enfoques que incluyan más y nuevos factores que permitan que el diagnóstico sea aún más completo si se emplean escalas cuantitativas. 
El análisis de los factores que inciden en la productividad reveló que el factor denominado mano de obra (MO) es preponderante pues es un elemento transversal en los procesos productivos, se encontró que, aunque la mano de obra presente en planta no tiene niveles elevados de escolaridad contribuye a incrementar los niveles de productividad de las empresas de manera decisiva, esto es claro pues la mano de obra (MO) opera los equipos y máquinas (MAq), modifica los entornos laborales (MA) a través de un elemento preponderante que son las relaciones interpersonales que en este estudio se lo mostró como "clima organizacional". Se observó que el personal de planta emplea adecuadamente la materia prima (MP), en los cálculos obtenidos se encontró que la eficiencia del uso del cuero hidrofugado y del cuero de refuerzo alcanzan valores del 99.2\%; esta misma mano de obra contribuye a que los ambientes de trabajo (MA) sean adecuados para desarrollar sus labores al mantener sus sitios de trabajo limpios, ordenados y en buenas condiciones. Se pudo ver que la mano de obra muestra buena actitud para colaborar con sus jefes y subordinados lo que influye en el clima organizacional; sin embargo, hay problemas para trabajar en equipo y tomar decisiones inherentes a sus funciones, esto pude deberse al nivel de escolaridad que ya se mencionó. Los cálculos mostraron que la disponibilidad de maquinaria (MAq) va desde el $98.95 \%$ es decir es elevada, significa que menos del $2 \%$ del tiempo que se necesita esta sufre paras a causa de mantenimiento si comprendemos que las máquinas son uno de los recursos empleados en la producción cuanto menores son las paras de máquina mayor es el nivel de productividad

Se pudo identificar que los años de permanencia en el mercado de las empresas y la mano de obra experimentada ha influido en la calidad del producto. La revisión de los reportes de ensayos de calidad del producto reveló que esta supera los requerimientos de las normativas como la norma INEN - ISO 20346:2014, se encontró que de los ensayos efectuados el $12 \%$ determinan incumplimiento, y el $88 \%$ muestran cumplimiento. Estos datos por un lado pueden ser preocupantes y por otro alentadores debido a la rigurosidad de los ensayos y los bajos costos de operación de los procesos productivos. Los niveles de calidad del producto se pueden incrementar optimizando los elementos del proceso: capacitación al personal, inversión en equipos y maquinaria, mejora de los ambientes de trabajo entre otros. Otras formas de mejorar la calidad del producto son la estandarización y normalización de los procesos, el control de costes y la profesionalización del talento humano que labora en el sector. Para cuantificar la incidencia efectiva de los elementos del proceso sobre la productividad resulta interesante abordar nuevos modelos que cuantifiquen los aportes individuales de cada factor en resultado del modelo.

\section{Contribuciones de los autores}

En concordancia con la taxonomía establecida internacionalmente para la asignación de créditos a autores de artículos científicos (https://casrai.org/credit/). Los autores declaran sus aportes en la siguiente matriz de contribuciones: 


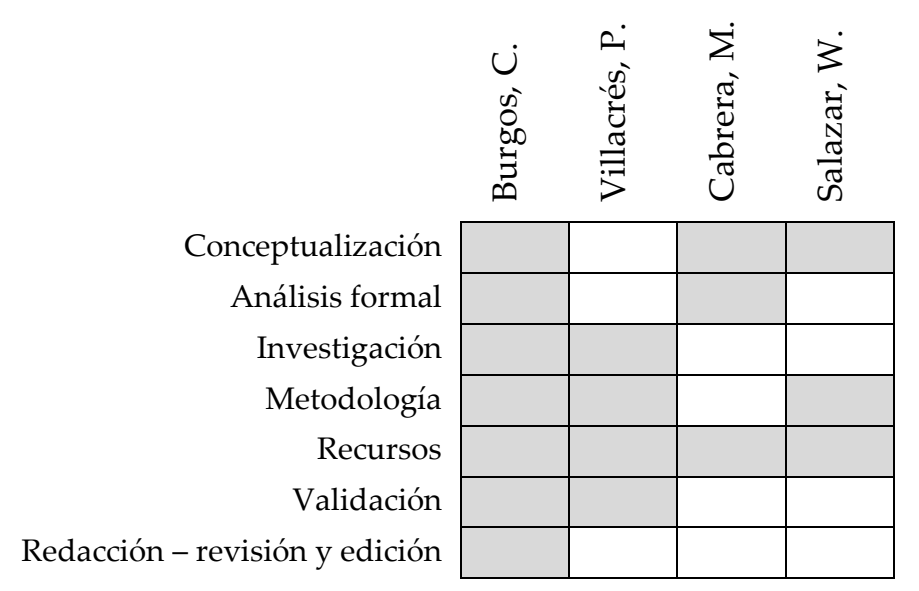

\section{Conflicto de Interés}

Se expresa que en el desarrollo del presente artículo no existen conflictos de intereses ni personales ni de ningún tipo por parte de los autores.

\section{Agradecimiento}

Agradecemos a las empresas productoras de calzado que dieron apertura para obtener, validar y actualizar la información aquí expuesta.

\section{Referencias}

Acosta, J. F., \& Rodríguez, J. O. (2008). Factores externos e internos determinantes de la orientación de la cultura estratégica de las empresas. Investigaciones Europeas de Dirección y Economía de la Empresa, 14(1), 13-32. Recuperado de https://www.sciencedirect.com/science/article/pii/S1135252312600094

Adam, J. A. (2005). Los métodos de valuación de empresas y su relación con la capacidad de las organizaciones para generar valor. Propuesta para reportar en la información financiera el valor de las organizaciones y su capacidad para generarlo. Contaduría y Administración, (217),11-47. https://www.redalyc.org/pdf/395/39521702.pdf

Agudelo-Orrego, B. E. (2019). Formación del talento humano y la estrategia organizacional en empresas de Colombia. Entramado, 15(1), 116-137. https://doi.org/10.18041/19003803/entramado.1.5383

Arévalo, W. I. (2021). Análisis económico del cantón Cevallos del sector calzado de la provincia de Tungurahua del período 2017-2019 (Proyecto de investigación previo a la obtención del título de Economista), Universidad Técnica de Ambato, Ambato: Ecuador. https://repositorio.uta.edu.ec/bitstream/123456789/32471/1/T4960e.pdf 
Benítez, M. K., Martínez, J. P., Margalina, V. M., \& Valencia, E. R. (2020). Análisis de la estructura de mercado de las sociedades de la cadena productiva de calzado en Ecuador. $\begin{array}{lllll}\text { Economía: } \quad \text { teoría } & \text { y } & \text { 9áctica, } & \text { (52), }\end{array}$ https://doi.org/10.24275/etypuam/ne/522020/benitez

Bernal, D. (2019). Factores internos y externos de crecimiento empresarial en micro empresas Mexicanas. Ciencias Administrativas. Teoría Y Praxis, 14(2), 27 - 39. Recuperado a partir de https://cienciasadmvastyp.uat.edu.mx/index.php/ACACIA/article/view/193

Bohórquez, L. E., Caro, A. S., \& Morales, N. D. (2017). Impacto de la capacitación del personal en la productividad empresarial: Caso Hipermercado. Dimensión Empresarial, 15(1), 210-220. Recuperado de http://www.scielo.org.co/pdf/diem/v15n1/1692-8563-diem-15-01-00210.pdf

Bonilla, Y. M., \& Mayorga, J. Z. (2013). Medición de la productividad y competitividad sector de la industria del calzado en la ciudad de Bogotá DC. En XVIII Congreso Internacional de Contaduría, Administración e Informática. México D.F. Recuperado de http://congreso.investiga.fca.unam.mx/docs/xviii/docs/1.25.pdf

Calderón, A., Dini, M., \& Stumpo, G. (Eds) (2016) Los desafíos del Ecuador para el cambio estructural con inclusión social. Naciones Unidas CEPAL S.16-01309. https://repositorio.cepal.org/bitstream/handle/11362/40863/1/S1601309_es.pdf

Camino-Mogro, S., Armijos-Bravo, G., \& Brito-Gaona, L. F. (2020). Productividad empresarial en el sector manufacturero y crecimiento económico en Ecuador para el período 2007-2017. En Muñoz-Suárez, M. A. (Compilador), Gestión estratégica, crecimiento económico y productividad. Machala: Ecuador. Recuperado de http://repositorio.utmachala.edu.ec/bitstream/48000/15734/3/CAP-3.pdf

Campaña, M. E. (2021). Plan de Negocios para la Comercialización de Calzado Ecuatoriano personalizado para damas y niños en la ciudad de Quito (Trabajo de titulación previo a la obtención del título de Ingeniería Comercial), Universidad Internacional del Ecuador, Quito: Ecuador. Recuperado de https://repositorio.uide.edu.ec/bitstream/37000/4536/1/T-UIDE-1384.pdf

Chan, J. F., Moralez, M. A. \& Canto, A. M. (2019). Panorama de la industria del calzado en el municipio de Ticul, Yucatán y su análisis desde la perspectiva de la competitividad sistémica. Repositorio de la Red Internacional de Investigadores en Competitividad, 13, 188206. En XIII Congreso Red de Investigación en Competitividad. Mérida: México. Recuperado de https://riico.net/index.php/riico/article/view/1792/1552

Chávez, G., Campuzano, J. \& Betancourt, V. (2018). The micro, small and medium enterprises. Classification for its study in the Accounting and Auditing Engineering career of the Technical University of Machala. Conrado, 14(Supl. 1), 247-255. Recuperado de http://scielo.sld.cu/pdf/rc/v14s1/1990-8644-rc-14-s1-247.pdf

Chimarro, V. V., Mora, V. E., \& Rueda, C. E. (2015). Diseño de un plan de marketing estratégico para el posicionamiento de marca de calzado Gamos con el objetivo de incrementar su participación en el mercado de la ciudad de Quito. ( Trabajo de 
titulación previo a la obtención del título de Ingenieras Comerciales). Universidad Politécnica Salesiana. Quito: Ecuador.

https://dspace.ups.edu.ec/handle/123456789/8196

Comisión Económica para América Latina y el Caribe -CEPAL, (2016), Los desafíos del Ecuador para el cambio estructural con inclusión social (2). Recuperado de: https://repositorio.cepal.org/bitstream/handle/11362/40863/1/S1601309_es.pdf

Córdova, F., Duque, G., \& González, M. (2018). Responsabilidad social empresarial. Una visión desde el endeudamiento y el empleo. VII Congreso Internacional de Ciencias Administrativas (pág. 37-49). CIDE Editorial: Ecuador. Recuperado de https://www.researchgate.net/publication/328150418_Responsabilidad_social_empr esarial_Una_vision_desde_el_endeudamiento_y_el_empleo

Cotler, P. (2015). Crédito de proveedores, tamaño de empresa e informalidad. El trimestre económico, 82(327), 559-582. Recuperado de

http://www.scielo.org.mx/scielo.php?script=sci_arttext\&pid=S2448-

718X2015000300559\&lng=es\&tlng=

Cruz, L. (2010) Estructura del clima organizacional. POIESIS Revista Electrónica de Psicología Social FUNLAM (20).

https://www.researchgate.net/publication/315448920_Estructura_del_clima_organiz acional

Erazo, J. C., \& Narváez, C. (2020). La gestión del capital intelectual y su impacto en la efectividad organizacional de la industria de cuero y calzado en la Provincia de Tungurahua-Ecuador. Revista Espacios, 41(21).

https://www.revistaespacios.com/a20v41n21/a20v41n21p20.pdf

Espinoza, G. A. (2017). Estudio para la producción y comercialización de calzado de seguridad industrial en la Asocación CALZAFINCE del cantón Cevallos (Trabajo de titulación previo a la obtención del título de Ingeniería de Marketing y Gestión de Negocios) Universidad Técnica de Ambato. Ambato: Ecuador. https://repositorio.uta.edu.ec/bitstream/123456789/24557/1/482\%20MKT.pdf

Flores, M., Medina, D., Vargas, D., \& Remache-Vinueza, B. (2020). Asignación de modelos de mantenimiento basada en la criticidad y disponibilidad del equipo. CienciAmérica, 9(4), 27-34. https://dialnet.unirioja.es/servlet/articulo?codigo=7746457

Fontalvo-Herrera, T. J., Hoz-Granadillo, E. \& Morelos-Gómez, J. (2018). La productividad y sus factores: incidencia en el mejoramiento organizacional. Dimensión Empresarial, 16(1), 47-60. https://dialnet.unirioja.es/servlet/articulo?codigo=6233008

García, G. J., Cazallo, A., Barragán, C. E., Mercado, M, Olarte, L., \& Meza, V. (2019) Indicadores de Eficacia y Eficiencia en la gestión de procura de materiales en empresas del sector construcción del Departamento del Atlántico, Colombia. Revista Espacios 40(22). http://www.revistaespacios.com/a19v40n22/a19v40n22p16.pdf

Instituto Nacional de Estadísticas y Censos - INEC (2019), Producción de la Industria Manufacturera. Recuperado el 11 de junio de 2021, de https://www.ecuadorencifras.gob.ec/produccion-industria-manufacturera/. 
Jaimes, L., Luzardo, M., \& Rojas, M. D. (2018). Factores Determinantes de la Productividad Laboral en Pequeñas y Medianas Empresas de Confecciones del Área Metropolitana de Bucaramanga, Colombia. Información Tecnológica, 29(5), 175-186. https://dx.doi.org/10.4067/S0718-07642018000500175

Kellermans, F.; Eddleston, K.; Barnett, T., \& Pearson, A. (2008). An exploratory study of family member characteristics and involvement: effects on entrepreneurial behavior in the family firm. Family Business Review, 21 (1): 1-14. https://doi.org/10.1111/j.17416248.2007.00107.x

López-Gómez, E. (2018). El método Delphi en la investigación actual en educación: una revisión teórica y metodológica. Educación, 21(1), 17- 40. Recuperado de https://www.redalyc.org/pdf/706/70653466002.pdf

Mayorga, C. A., Ruiz, M., Mantilla, L. M., \& Moyolema, M. (2015). Procesos de producción y productividad en la industria de calzado ecuatoriana: caso empresa Mabelyz. ECA sinergia, 6(2), 88-100. Recuperado de https://revistas.utm.edu.ec/index.php/ECASinergia/article/view/331

Mejía-Giraldo, A., Bravo-Castillo, M., \& Montoya-Serrano, A. (2013). El factor del talento humano en las organizaciones. Ingeniería industrial, 34(1), 2-11. Recuperado de https://www.redalyc.org/pdf/3604/360433593002.pdf

Ministerio de Industrias y productividad (MIPRO). (2016). Reglamento Técnico Ecuatoriano RTE INEN 264. DO. 788. Recuperdao de https://www.normalizacion.gob.ec/buzon/reglamentos/RTE-264.pdf

Morales-Ramos, L. V., Morales-Ramos, K. E., Valle-Álvarez, A. T. (2017). Crecimiento y supervivencia empresarial en el sector de fabricación de calzado en Ecuador. $\begin{array}{llll}\text { Panorama } & \text { Económico } & 25 & \text { 43-56. }\end{array}$ https://dialnet.unirioja.es/servlet/articulo?codigo=6839609

Palacios, A. M. (2017). Obligaciones y derechos tributarios que tienen los contribuyentes, personas naturales obligadas a llevar a contabilidad pertenecientes a los segmentos de micro empresas y pequeñas empresas en el Ecuador. Pontificia Universidad Católica del Ecuador. (Tesis de Maestría previa a la obtención del titulo de Magíster en http://repositorio.puce.edu.ec/bitstream/handle/123456789/13015/TESIS\%20ANA\%2 0LUCIA\%20PALACIOS.pdf?sequence=1\&isAllowed=y

Render, B. \& Heizer, J. (2017) Principios de administración de Operaciones (9na ed). México D.F., México: Pearson Educación.

Revelo, K. V. (2016). Estudio de factibilidad para la creación de una microempresa productora y comercializadora de leche y queso a base de soya en la Ciudad de Ibarra, Provincia de Imbabura (Previo a la obtención del título de Ingeniería en Contabilidad y Auditoría C.P.A.) Universidad Técnica del Norte, Ibarra: Ecuador. http://repositorio.utn.edu.ec/bitstream/123456789/6657/1/02\%20ICA\%201169\%20TR ABAJO\%20GRADO.pdf 
Romero, D. (2018). Zapatos ecuatorianos, con un mercado cuesta arriba. Recuperado de https://www.vistazo.com/enfoque/zapatos-ecuatorianos-con-un-mercado-cuestaarriba-ADVI122031

Saltos, J. G., Jiménez, W. F., \& López, Z. E. (2017). Los Sistemas de Gestión de Calidad y la conformidad de la norma: un caso de estudio del sector de producción de plantas de calzado, República del Ecuador. Revista Publicando, 4(11), 620-644. Recuperado a partir de https://revistapublicando.org/revista/index.php/crv/article/view/614

Servicio Ecuatoriano de Normalización (2020), Catálogo de Documentos Normativos Vigentes. http://apps.normalizacion.gob.ec/descarga/

Torgler, B., \& Schneider, F. (2007). What shapes attitudes toward paying taxes? Evidence from multicultural European countries. Social Science Quarterly, 88(2), 443- 470. https://doi.org/10.1111/j.1540-6237.2007.00466.x 